To cite this article please refer to final published version: Paul Hanna \& Matthew Adams (2017): Positive selfrepresentations, sustainability and socially organised denial in UK tourists: discursive barriers to a sustainable transport future, Journal of Sustainable Tourism, DOI: 10.1080/09669582.2017.1358272

To link to this article: $\underline{\text { http://dx.doi.org/10.1080/09669582.2017.1358272 }}$

\title{
Positive self-representations, sustainability and socially organised denial in UK tourists: discursive barriers to a sustainable transport future
}

\author{
Paul Hannaa and Matthew Adamsb
}

aSchool of Hospitality and Tourism Management, University of Surrey, Guildford, United Kingdom; bSchool of Applied Social Sciences, University of Brighton, Brighton, United Kingdom

\begin{abstract}
This paper provides an empirical application of some recent developments in the social science of sustainability to understanding sustainable transport behaviour. We analyse talk about holidaymaking taken from interviews with self-defined "eco" or "sustainable" tourists. The focus of this paper explores the ways in which participants understand and reconcile the potential conflict of air transport and the notion of sustainable holidays. We identify a number of discursive strategies participants used to project and maintain positive self-representations in the context of complex, often incompatible constructions of sustainability derived from this particular dilemma. Such strategies are considered as concrete examples of the psychosocial organisation of denial and thus offer discursive barriers to sustainable transport futures. However, the analysis also demonstrates the ways in which some individuals were able to resist or challenge such forms of socially organised denial. The potential implications of these discursive barriers and strategies for sustainable transport futures and the tourism sector are discussed.
\end{abstract}

\section{Keywords}

Sustainable transport; denial; discourse; sustainable barriers; transport futures

\section{Introduction}

Whilst the nature and scope of anthropogenic climate change has been established (e.g. Hartmann, Tank, \& Rusticucci, 2013), it is generally acknowledged that political and collective action has been slow (Freudenburg \& Muselli, 2013). Although the energy sector and industry practices are largely held responsible for extensive pollution and greenhouse gas emissions, increasing levels of political rhetoric urge individual members of society to take some responsibility for their consumption and lifestyle choices. The logic inherent in such rhetoric is that changes in individual behaviour, if adopted by sufficient numbers, will amount to a collective reduction in carbon-intensive activities, and move us, as a society, towards a more sustainable future (Micheletti, 2003). 
Attendant definitions of 'sustainable' behaviour are often ambiguous, especially as they are translated into everyday contexts. We are faced with a plethora of injunctions to behave and consume in a 'green', 'ethical', 'eco-friendly' or 'sustainable' fashion. Many commercial sectors now create products and services that are marketed as sustainable, including the tourism industry. A range of tourism products (e.g. eco-tourism, sustainable tourism, green tourism, and ethical tourism) have entered the market, providing avenues for avowedly more sustainable behaviour (Croall, 1995; France, 1997; Hunter, 2002a, 2002b; Mowforth \& Munt, 2003; UNEP, 2014). Such products offer consumers the potential to register their 'ethical' credentials through a tourism product that attempts to mitigate some of the social and environmental impacts commonly associated with mainstream tourism. Whilst a definitive definition of sustainable tourism is problematic (Weaver, 2006), examples have included: hotel energy saving practices (Chan \& Lam, 2003); adaptive resource management at destinations (Larson \& Poudyal, 2012); craft market cooperatives (McGehee \& Meares, 1998); and ecomuseology (Bowers, 2016), to name but a few. It is in this context that the tourism industry is presented as both a cause and a solution in relation to environmental problems.

However, whilst 'sustainable tourism' potentially provides a more sustainable form of tourism consumption, it often involves unsustainable forms of tourism transport, especially long-haul flights - incontrovertibly regarded as unsustainable in their current form (Gössling et al., 2007; Hall, Scott, \& Gössling, 2013). This contradiction clearly creates the potential for cognitive dissonance amongst consumers of tourism (Miller, Rathouse, Scarles, Holmes, \& Tribe, 2010). Stretching back to Festinger's foundational work on cognitive dissonance (Festinger \& Carlsmith, 1959), social psychologists have established that human responses to cognitive dissonance can involve changing behaviour to reduce dissonance (e.g. ceasing to fly long-haul), but more often than not involve the less onerous alternative of changing attitudes, beliefs, even values, to avoid dissonance (Cooper, 2012). In other words, we routinely adjust what we think about our behaviour to justify it, rather than the reverse, and this reasoning extends to sustainable behaviour (Gifford, 2011; Gifford \& Nilsson, 2014). The logic of cognitive dissonance, therefore, could be taken to suggest it operates as a primary barrier to the wholesale adoption of the types of sustainable transport futures highlighted in this special issue and elsewhere (e.g. Metz, Sohr, Bei, Wölki, \& Behrisch, 2016; Poullikkas, 2015).

Some evidence of this form of dissonance exists (e.g. Miller et al., 2010), or is implied in tourists' conflicting understandings of their transport practices (e.g. Becken, 2004); in the suggestion that the holiday provides a specific understanding and context that makes sustainable behaviours particularly difficult (Barr, Shaw, Coles, \& Prillwitz, 2010), including their transport behaviours (Hares, J. Dickinson, \& Wilkes, 2010); and in the emotional responses present when questioning such behaviours (Randles \& Mander, 2009). However, little has been done to fully conceptualise if and how dissonance is experienced and resolved in the everyday context of tourism and travel decision-making. A recent publication in this journal (Hanna, Scarles, Cohen, \& Adams, 2016) provided some understanding into the ways in which contemporary climate change discourses exonerate individual responsibility, acting as obstacles to collective climate change action. In addition, 
Kurz, Donaghue, Rapley, and Walker (2005, p. 606) examine the ways in which 'average citizens' "construct, represent, and account for their own environmentally relevant practices", arguing that dominant ways of talking create 'discursive barriers' to pro-environmental practices. Thus, whilst these accounts offer different areas for investigation, both explore ways in which talk surrounding sustainability potentially operate as barriers to the individual adoption of more sustainable behaviour. More specifically, discursive barriers are defined in the context of this paper as identifiable patterns - or 'storylines' (Imran \& Pearce, 2015) - in written or spoken communication that discourage, directly or indirectly, addressing a problem or set of problems - in this case, issues relating to (un)sustainable travel and tourism.

It is in this context that this paper engages with the discursive barriers tourists face when considering the types of desirable/sustainable forms of tourism transport highlighted in this special issue and elsewhere (e.g. Gronau, 2016). To provide the context for how this article will engage with such issues, emerging literature on 'socially organised denial' (Norgaard, 2011) is now presented to suggest how recent theoretical insights extend beyond conceptualisations of cognitive dissonance, enabling us to explore tourists' accounts of (un)sustainable travel practices.

\section{Addressing social context}

A range of scholars have attempted to understand sustainable and unsustainable behaviour though attitudes, motivations, norms and social comparison processes (e.g. Fielding, Terry, Masser, \& Hogg, 2008; Rabinovich, Morton, Postmes, \& Verplanken, 2012). There have been numerous related efforts to 'profile' the environmentally conscious individual in terms of demographic characteristics and/or environmental attitudes/beliefs in a range of settings from 'ethical consumption' to 'sustainable tourism' (e.g. Barber, 2014; Dolnicar, 2004, 2010; Dolnicar, Crouch, \& Long, 2008; Dolnicar \& Leisch, 2008; Luzar, Diagne, Ecgan, \& Henning, 1998; Van Liere \& Dunlap, 1980). However, demographic profiling research has received extensive criticism for failing to consider how engagement with such practices reflects new forms of class based distinction (Adams \& Raisborough, 2008). Further, recent research has drawn on the insight, long established in social psychology (Potter \& Wetherell, 1987), that whilst people's attitudes might 'predict' their expected behaviours, attitudes are only weakly correlated with actual behaviour - the fabled 'attitude-behaviour gap' (Kollmuss \& Agyeman, 2002). In the context of 'pro-environmental behaviour' in tourism, pro-environmental attitudes do not automatically imply that proenvironmental behaviours will be practiced (e.g. Juvan \& Dolnicar, 2014).

The pronounced 'gap' between attitude and behaviour is one aspect of a necessary corrective, well underway in psychology and the social sciences, to the depiction of a calculating, self-interested, information-deficient but otherwise rational individual upon which injunctions to behave more sustainably have often relied. There has been, to paraphrase Leggett (2014), a foregrounding of human fallibility in recent attempts to make sense of (un)sustainable behaviour. Psychologists have subsequently articulated many variants of the psychological 'barriers' that mitigate active behaviour change in the light of information about anthropogenic ecological degradation, and elucidated the attitude- 
behaviour disjuncture. Gifford's (2011) overview includes cognitive, behavioural, perceptual and social cognitive barriers (see also Gifford \& Nilsson, 2014). However, a 'critical consensus' is emerging in otherwise varied approaches to sustainable behaviour (Adams, 2014), which, at its simplest, asserts that the relationship between social context and the individual must be considered much more extensively, if we are to grasp how opportunities for sustainable behaviour emerge (Uzzell \& Räthzel, 2009).

Research in the areas of 'sustainable lifestyles' (e.g. Cooper, Green, Burningham, Evans, \& Jackson, 2012; Evans \& Jackson, 2007; White \& Stirling, 2013) and 'sustainable social practices' (e.g. Darnton, Verplanken, White, \& Whitmarsh, 2011; Shove, 2010; Spurling, McMeekin, Shove, Southerton, \& Welch, 2013; Warde, 2005) has been more social in orientation. However, such approaches have not escaped critique. For example, social practice approaches have been challenged for being overly deterministic (e.g. Sayer, 2012), sharing the same premise as behavioural economics in emphasising a tendency for individuals not to reflect on social practices: invoking "the facts of automatic, repetitive and mindless conduct' (Warde, 2013, p. 3). In addition, 'social practices' and 'sustainable lifestyles' research tends to focus on the 'everyday', leaving tourism and other means of 'escape' largely ignored (Bedford, Burningham, Cooper, Green, \& Jackson, 2011; Davison, 2012; Dillard \& Bates, 2011; Yeoman, Brass, \& McMahon-Beattie, 2007).

Therefore, whist these two contemporary approaches do offer an account of the 'social' that has largely been ignored, we once again return to the question of why is it the case that we are not sufficiently motivated to try and alter our tourism transport behaviour, when we are increasingly told that such behaviour is negatively impacting on the wider environment in ways that are, or will, undermine our own wellbeing? Whilst it is important to acknowledge the role of social context in addressing these questions, the psychological and subjective dimensions must simultaneously remain in focus. Recent trends in social psychology, environmental psychology and sociology might offer some scope here in respect to research on self-representation and psychoanalytic defence mechanics as significant ways to understand barriers to individual behavioural change, within a social context, and in relation to desirable transport futures.

\section{Defence mechanisms as barriers to pro-environmental behavioural change}

Defence mechanisms were originally conceived of by Sigmund Freud, and developed further by successive generations of psychoanalysts. Freud initially conceived of 'defences' as a way of halting or hindering the expression of our unruly instinctual demands by 'splitting' them off from conscious awareness (e.g. S. Freud, 1894). Anna Freud subsequently differentiated various types of defence mechanisms (A. Freud, 1992), and the list has been extended, modified and debated ever since (e.g. Blackman, 2004). In contemporary accounts, defence mechanisms can arise whenever we are confronted with anxiety-inducing situations, in which anxiety is induced via a threat to our individual or social identities. In order to reduce anxiety, humans unconsciously protect themselves against unwanted thoughts, feelings, and desires by using defence mechanisms to disguise and contain their anxiety. The list of defence mechanisms conceptualised today includes denial, repression, regression, displacement, projection, reaction formation, intellectualization, rationalization and 
sublimation (Kramer, 2010).

Situations that induce anxiety might well include the experience of cognitive dissonance, which, as we noted above, arises in situations where potential behaviour is in conflict with established values, attitudes or beliefs. Despite originating in different traditions then (psychoanalysis and social psychology), work on defence mechanisms presents us with an established taxonomy of how people may seek to resolve dissonance. More specifically, if we accept that sustainable tourism involving long-haul flights presents an anxiety-inducing state of cognitive dissonance, defence mechanisms might be a relevant starting point for making sense of how we resolve that dissonance.

Although initially developed to account for social patterns in how we respond to knowledge of human suffering, Cohen's typology of denial (Cohen, 1996; 2001) has influenced theory and research into defence mechanisms relating to knowledge of ecological degradation (e.g. Adams, 2016; Norgaard, 2011). Cohen defines denial as 'an unwillingness to accept the reality of uncomfortable, painful facts (and/or unconsciously) the repression of such facts... a state of knowing and not knowing at the same time' (2013, p. 72-3). Cohen distinguishes between three types: literal, implicatory and interpretive denial. Literal denial involves denying something exists or has happened at all. In relation to ecological crisis, it might involve outright rejection of that crisis as a reality - 'the evidence does not point to global warming at all'. Interpretive denial involves the partial acceptance of a phenomenon, though interpreted in a way which reduces the anxiety associated with contemplating it. In the context of environmental problems, this form of denial may be evident in the interpretation of anthropogenic climate change as 'natural' fluctuations, emphasise our inability to intervene, or exaggeratedly stress the benefits of anthropogenic climate change for human societies. Note the problem is not refuted per se, it is reinterpreted. Finally, implicatory denial involves accepting the reality of a thing or event, and possibly even standard interpretations of aspects such as cause or context, whilst reducing the significance of it in some way - and in doing so, the implications for one's own behaviour (Cohen, 2013). A straightforward example here might be the construction of climate change mitigation solely as a technical problem that requires the attention of engineers and scientists, whilst individuals and societies can carry on as normal.

It is worth noting here that the category of implicatory denial can incorporate a number of established defence mechanism concepts, prime amongst which are splitting and projection. There is no space here to describe the origin or detail of these variations, but briefly, splitting involves the simplification and polarisation of aspects of reality to avoid emotions that threaten a positive sense of self. 'Bad' is externalised, split off from one's good self. The 'bad' is often projected onto something else that reduces the sense of threat - other individuals, groups, places or times. An example in the context of environmental issues might be the tendency to consider problems as being far in the future - a sense of responsibility, a fear of loss or change is split off from the present and projected into a distant (and therefore 'safe') future (J. L. Dickinson, 2009; Hamilton, 2013; Opotow \& Weiss, 2000; Randall, 2009).

INSERT FIGURE 1 HERE 
Despite the different terminology, rooted in different theoretical traditions, links between the conceptualisation of cognitive dissonance and defence mechanisms are discernible here, such as in the similarity between splitting and attempts to reduce the importance of dissonant cognitions by entertaining alternatives. These alternatives do not replace the dissonant cognitions, but the division (or split) of energy into dissonant and consonant cognitions reduces their overall impact - and, therefore, the need to act. Similarly trivialization as a mode of dissonance reduction (e.g. Simon, Greenberg, \& Brehm, 1995) closely parallels foundational descriptions of the defence mechanism of rationalization (A. Freud, 1992; Sperling, 1958). There are many such parallels and overlaps. Cohen's typology also has many correspondences with other research highlighting denial mechanisms in this context, lending further credence to his conceptualisation (Lorenzoni, Nicholson-Cole, \& Whitmarsh, 2007; Opotow \& Weiss, 2000; Stoll-Kleemann, O'Riordan, \& Jaeger, 2001).

\section{Socially organized denial and barriers to environmental behaviour}

Although defence mechanisms have historically been researched "almost exclusively at the individual level as a psychological phenomenon" (Norgaard, 2006a, p. 389), following Cohen, sociologically-oriented analysis has identified both the psychological and the social/collective processes involved in denial and related defence mechanisms (e.g. Cohen, 2012). In fact, in a brief discussion of climate change Cohen explicitly stated that "a working conception of denial ... should make sense in both psychological/ individual and social/collective terms" (2012, p. 73). In the context of environmental concerns, there have been numerous accounts highlighting how individuals draw on meanings and conventional understandings within culture and society to deny the implications of climate change and related environmental issues for our own behaviour. This drawing upon existing 'stocks of knowledge', shared and maintained with others, to defend ourselves against the reality and scope of change required, is what Norgaard (Norgaard, 2006b, 2011) refers to as the 'social organization of denial' (see also Cohen, 2012; J. L. Dickinson, 2009; Hollander, 2009; Lertzman, 2010; Opotow \& Weiss, 2000; Randall, 2009).

From the perspective of socially organized denial, emotional, unconscious, 'internal' registers of defence mechanisms, arising in response to uncomfortable emotions generated by information implicating humans in ecological degradation (J. L. Dickinson, 2009; Hollander, 2009; Randall, 2009; Weintrobe, 2010), are readily channelled into 'external' culturally sanctioned understandings and behaviours, ones that allow individuals to carry on with 'business-as-usual' (Cohen, 2013). Anxiety is induced by the knowledge that our actions contribute to climate change - alongside an array of related emotions including helplessness, guilt and generalized threats to established identities. From this perspective, when confronted by such painful emotions, we find ways of avoiding or dampening them, such as by shifting "attention to positive self-representations, and - especially in terms of the emotion of guilt by framing them in ways that [minimise] their potency" (Norgaard, 2006a, p. 384).

'Social organization' therefore encompasses the way information about ecological crises are framed and mediated, including political and ideological representations and communication (Jacques, Dunlap, \& Freeman, 2008; Lakoff, 2010; Randall, 2009). In addition, such issues have been explored in research interested in the interpersonal and group dynamics of defence mechanisms in this context (e.g. Opotow \& Weiss, 2000; Rustin, 2010; 
Weintrobe, 2010). Research has adopted methods that have included ethnography (Norgaard, 2006a, 2011), focus group studies (Stoll-Kleemann et al., 2001); interviews (Hugh-Jones \& Madill, 2009; Kurz et al., 2005), and analysis of printed commentary (Dunlap \& Jacques, 2013).

There is undoubtedly still plenty of scope for "exploring the ways in which talk (with talk understood as social action in its own right) may in and of itself work to contribute to or to undermine - the adoption of more environmentally sustainable conduct" (Kurz et al., 2005 , p. 605). In this paper, we attempt to answer this call by focusing on discursive strategies as vehicles for socially organised forms of denial, offering some insight into the ways in which narratives facilitate or inhibit tourist transport behaviours and the implications of these barriers on enabling the uptake of desirable transport futures.

\section{Methodology}

In order to explore such issues semi-structured interviews were identified as an appropriate method for generating the data. Despite the plethora of data-collection methods available to the qualitative researcher, including photographs (e.g. Scarles, 2012), internet blogs (Magnini, Crotts, \& Zehrer, 2011), comments pages (e.g. Koteyko, Jaspal, \& Nerlich, 2013), to name but a few; this paper utilised the semi-structured interview as it offers the researcher synchronous communications in time and space through which rapport is easily established, social cues are visible, and the interviewees' interactions and responses to the interviewer are the unit of analysis (e.g. Opdenakker, 2006). The interview data presented in this article was part of a larger project exploring the psychosocial dynamics involved in sustainable tourism participation - including choosing and booking a holiday, examining what the participants did on holiday and how they make sense of their experiences; and finally, a reflection on their experience and future plans. This structure draws on Gergen and Gergen's notion of 'emplotment' (1986) - the active assembly of events involving self and others into a narrative identity. Locating the holiday in a sequence of events enables the researcher to appreciate the difficult task of negotiating different identity positions within a coherent narrative frame (Bagnoli, 2004). Through such negotiation it is argued that the speaker attempts to produce an intelligible account of an episode, claiming a 'moral identity' through the resolution of often inconsistent positions (Ochs \& Capps, 1996), and performing 'identities' through talk (Lawler, 2008).

In this article, we focus on a particular moment of emplotment - how our participants constructed their decision to use, or not to use, air transport as part of their sustainable holiday. Although this moment arose in different ways in different interviews, it was nonetheless a consistent theme across them all. We feel there is value in highlighting this specific moment, as it speaks to a potentially acute instance of cognitive dissonance and might be expected, therefore, to invite talk which reflects defence mechanisms. More broadly, it addresses a call made by Lorenzoni et al. (2007, p. 448) for research to ask "how do people reconcile their awareness and concern about climate change with lifestyle choices and pressures?". However, we should make it clear that the point here is not to hold up dynamics of denial as a way of diminishing or judging the nature of participants' responses. 
Our intention is to "[help] us to address the challenges faced by people struggling to identify and confront the collective problems with which their own everyday life-activities are entwined" (Soron, 2010, p. 117); including an understanding of the barriers related to the specific issues of sustainable travel and tourism.

As noted earlier, providing a clear definition of the term 'sustainable tourism' is problematic if not impossible (Weaver, 2006). There is very little agreement within and between the tourism industry, politicians, academics, and the general public as to the actual meaning of 'sustainable' or 'sustainability' more generally (Butler, 1998). Therefore, sixteen participants were recruited on the basis that they self-defined as 'sustainable/eco/ethical/responsible/environmental' tourists. These 16 individuals were selfselecting through their direct response to an advert placed on websites and café notice boards in the South East of England. The purpose of such a strategy was not for the researchers to impose their prejudgements on what constitutes a 'sustainable' or 'ethical' tourist, but to instead engage with individuals who explicitly identify with, or define their practices through, these labels. Further, whilst such forms of tourism can be debated and particular labels favoured, in this paper the term 'sustainable tourism' has been selected as it “...is perhaps the most prominent feature of contemporary tourism discourse" (Higgins-Desbiolles, 2008, p. $347)$.

To embrace the notion of participant empowerment (e.g. Rappaport \& Stewart, 1997), and as an attempt to negotiate the tension between environmental issues and interviewer travel (e.g. Hanna, 2012) the choice of face-to-face, telephone or Skype interviews was given to all participants. As a result, ten participants chose face-to-face interviews (Anna, Amanda, Ben, Celia, Francesca, Gemma, Gillian, Hannah, James, Jayne), three chose telephone interviews (Christina, Denise, Julie), and three chose Skype interviews (Carly, Darren, Katy). Whilst there is much debate regarding the relative strengths and weaknesses of each research medium (Deakin \& Wakefield, 2013; Hanna, 2012; Holt, 2010), it is beyond the scope of this paper to offer a discussion. All interviews had been digitally recorded and were transcribed using 'Express Scribe' software. Interviews ranged in length from 31:16 to 1:15:58 minutes.

To examine the data, we drew on an eclectic approach utilising concepts from Discursive Psychology and Psychosocial Studies. Working with printed copies of the transcriptions we utilised Discursive Psychology (Potter \& Wetherell, 1987) to understand language as a social practice that has a performative function which individuals can actively use to manage stage, present emotions and offer particular identities/versions of the 'self' (Edwards, 2000; Speer \& Potter, 2000; Willig, 2008). Thus, our analysis paid particular attention to such aspects through our reading of the transcriptions. This enabled us to explore how individuals construct accounts of their travel behaviours in relation to their identities as 'sustainable tourists'. In addition, we attempted to enrich a Discursive Psychology approach by utilising terminology developed in Psychosocial Studies, namely the interdisciplinary accounts of denial that have been developed under this broad banner: reading our data with an eye for examples of the aforementioned 'mechanisms of denial' following Cohen and others, as forms of self-presentation, which are socially constructed and maintained (e.g. Norgaard, 2011). Thus, we adopted an action-orientated (language as doing something) 
understanding of denial, utilized within the specific parameters of the interview, as worked examples of the 'socially organized denial' described above.

\section{Findings}

Our attention now turns to our data to examine the ways in which the participants negotiate their tourism transport practices in relation to broader issues of climate change and sustainability. As Table 1 indicates, literal and interpretive denial are the less frequent defence mechanisms identified in our data. However, this finding is of little surprise given that literal and interpretive denial struggle as publically legitimate strategies (e.g. Hanna et al., 2016) which might be further enhanced due to the sample self-defining as sustainable. Therefore, much of what follows focuses on implicatory denial which is more subtle and nuanced. However, it should be noted that interpretive and implicatory denial are not clearly distinct in practice, indeed to deny implications, there is often a need to reinterpret the nature of the problem to some extent (Adams, 2016, pp. 135-138).

\section{INSERT TABLE 1}

\section{Literal \& interpretive denial}

When exploring the issue of air transport in relation to tourism and climate change Gillian, a 25-year-old female who flew for her holiday at an eco-resort on the Andros Islands, makes the following comments:

Umm I don't know how I feel about carbon footprints to be honest, I live in... well... my other half is a scientist and all my family are scientists and they kind of scup at the idea of a carbon footprint because it cancels itself out, I don't really understand how but they're all quite adamant that it's actually a government scare thing and I suspect that it may be mostly propaganda. I think that it probably does happen but I think that but not I don't think it's nearly as bad as (h) a lot of people say about that, it's just the latest thing though isn't it it's just the latest buzz word

In this extract the assertion of uncertainty ("I don't know how I feel"; "they kind of scup at the idea"; "I don't really understand how") occupies a space between literal and interpretive denial (Cohen, 2013). It reflects literal denial in that it combines awareness of a fact, with the failure to acknowledge the existence of that fact, disrupting the suggestion that anything is happening. The 'it' of the "government scare thing" here renders carbon emissions, and therefore anthropogenic climate change, as a fiction: a product of a conspiracy or 'propaganda' which lacks evidence, and perhaps masks a hidden agenda (Cohen, 2013, p. 73). But the talk quickly segues into something more like interpretive denial - it $i s$ happening, but the danger is exaggerated by vague consensus ("a lot of people say"), which is further delegitimised as superficial and transient ("latest thing", "latest buzz word"). In a similar 
light, when talking about her holiday volunteering in Quito, Anna comments "I have to say that all the business about sort of carbon footprints and so on, I'm really not that interested".

These strategies help to establish a positive self-representation - including a selfdefinition as a sustainable tourist - in response to the potentially troubling dissonance arising from the tension between flying and sustainable tourism. One is uncertain perhaps, but amidst knowledgeable company; and not gullible, or led by fashion - all of which draw upon and contribute to discursive barriers to behavioural change, and broader discourses surrounding climate change and climate responsibility (Hanna et al., 2016; Kurz et al., 2005). Our analysis is not intended to make a pejorative judgment about Gillian or Anna's motivations. The links between government 'scare' tactics, moral panics and propaganda that help to contextualise and legitimise Gillian's rationale for carbon footprint scepticism are understandable articulations of broader cultural narratives (Klein, 2015); which predominant sustainability discourses arguably do little to challenge (Johnston, Everard, Santillo, \& Robèrt, 2007).

\section{Implicatory denial \& moral licensing}

The following quote is taken from an interview with Jayne, a 48-year-old female who flew to Sir-Lanka for a holiday marketed as an 'eco-holiday', when she was asked if she saw any conflicts in relation to flying:

... no because we wanted to go somewhere hot for Christmas, so it you know it umm in a way I mean my friend who works for WWF she um she almost felt like, well it kind of like, it kind of checks and balances, it kind of makes up for the fact that were flying you know (h) um, no I mean yeah... you know this is the thing... I think if you were you know... there is that whole thing of would you go on holiday at all if you were being really eco-friendly?

In posing the rhetorical question "would you go on holiday at all if you were being really eco-friendly?", Jayne provides an example of extreme case formulation, a familiar trope in Discursive Psychology (Edwards, 2000; Speer \& Potter, 2000). The extreme case here is complete abstinence from the practice of holidaying. It functions to reduce the dissonance of flying/sustainability by highlighting the absurdity, the impossibility, of the available alternatives. This is accompanied by the comment "... it checks and balances, it kind of makes up for the fact we were flying you know" where the balance is made by her travel partner which offers an intriguing example of implicatory denial operating in discourse. Recall that implicatory denial is not an attempt to deny the presentation of facts or reality, or their conventional interpretation. 'What are denied or minimized are the psychological, political or moral implications that conventionally follow' (Cohen, 2001, p. 8). The reduction of dissonance, by dampening or removing the 'moral imperative to act' (Cohen, 2001, p. 9) is here managed in talk by the emplotment of one act (flying) in a broader ethical narrative incorporating many acts ("checks and balances"). It amounts to a public form of "moral selflicensing', whereby we 'license' morally questionable behaviour by reminding ourselves of good behaviour in the past (Merritt, Effron, \& Monin, 2010). 
Jayne's response continues as follows:

The two are sort of quite problematic I think really, particularly kind of going somewhere and having a really relaxing time and having people looking after you and waiting on you and all that kind of thing. That's not you know... you know you go to a third world country you know what the score is really before, the people are maybe living in a pretty sort of basic way so you have got to kind of, there are lots of things that are quite um, difficult to tolerate on that level really you know, it's hard to, but our overriding decision was to go somewhere hot for Christmas

The reference to the affective struggles of coming to terms with the living conditions of people in the tourist destination of the function to represent the self in a positive light and maintain the participants 'ethical identity', and license the "overriding" (i.e. uncontrollable) decision to "go somewhere hot for Christmas" - and, by implication, to fly there. Again, a subtle form of implicatory denial is at work here. The identified unsustainable component of the holiday - flying - is seen as important but located further down a hierarchy of what matters most - the need for a warm holiday, for contributing to a third world economy. In relegating flying in this way, its negative implications are significantly reduced. The introduction of a form of moral self-licensing, combined with extreme case formulation, expert rhetoric, and identity positioning, arguably function in combination to powerfully manage dissonance and maintain an implicatory form of denial.

For Carly, a participant who undertook a walking holiday in the UK, in addition to a 'responsible' holiday to India, when discussing her trip to India she negotiates her decision to fly through a similar set of discourses. As she comments:

(C) Because I had never been out of Europe before and I wanted to see a bit more of the world and umm I wanted to see the world in a way that was as responsible as possible. I accepted that flying to India wasn't necessarily that responsible but I wanted to do it in a way that was as responsible as possible and in a way, I was able to see some of the local culture and sort of be more absorbed in the local culture than if I was just going on holiday and being an observer, so yeah, I wanted to do some good even if it wasn't possible to do no harm

(I) and would you consider flying again in the future

(C) yes, if I am honest (h) I will probably feel guilty when I do it but yes, I would probably fly in the future umm, but I wouldn't make it a regular thing. If I did it would be a one off

Here Carly's decision to fly to India is negotiated through explicit reference to notions of responsibility. A delicate negotiation of dissonance is implicitly suggested here through reference to behaving as "responsible as possible" (twice) and regulating air transport behaviours through ensuring it is a "one off". Arguably, implicatory denial is again an active component of the discursive work here, though at a more complex level. The implications of 
emissions for climate change are not denied - they are folded into the moments of hesitation, uncertainty and provisos around comments about responsibility.

Further, the implications of flying long-haul are denied by being positioned as isolated ('never been out of Europe before; 'a one-off'); and diffused in a broader range of sustainable behaviours that, as above, arguably serve to 'license' unsustainable behaviour. In fact, in Carly's case, the moral accounting involved relies on a broader category of moral 'goods' - worldliness ('I wanted to see a bit more of the world'), and appreciation of culture ('more absorbed in the local culture') as well as being responsible. Positive selfrepresentations here function through the 'traveller - tourist' dichotomy, accentuated by a sustainable dimension (Caruana, Crane, \& Fitchett, 2008). By being active in her 'responsible' engagement with the host community, Carly constructs herself in opposition to the conventional 'rest and relaxation/observer' tourist (splitting and projection), which helps legitimise her position as a 'responsible tourist' and mitigate against the implications of her transport behaviours for sustainability.

\section{Implicatory denial, deservingness and accountability}

In an interview with Ben, an individual who embarked on a holiday to Greece booked through a 'responsible travel' website, he was asked if he saw any conflicts in flying to his destination and responded with the following comments:

Umm... we have driven, we have driven when we went skiing I actually drove... well I mean not really, I mean you know, we have been keeping air miles for a long time, it's like well actually we had planned to do the camping and we had been on a camping holiday, kind of like well no this is for us and we are going to treat ourselves, yeah so, no there wasn't really

Norgaard's (2011) notion of 'deservingness' can be utilised throughout the extract to see how such a rhetorical device functions in direct opposition to the regulation/restriction of air transport practices for tourism. Here the "long time" it took to save air miles for the holiday serves to legitimise the decision to fly and avoid the conflicts associated with being a 'sustainable' tourist through the hard work and effort put in to saving for such practices. Ben implicitly distances himself from the imaginary other that flippantly engages with air transport without a conscious effort for those actions (an example of splitting and projection perhaps). In this sense then a discourse of 'deservingness' functions to explain and validate his actions in relation to the conflict between his identity as a sustainable tourist and the more unsustainable practice of air transport. In addition, through reference to this holiday as a specific 'treat', notions of proximity and the exotic other associated with the holiday help to uphold and maintain the lack of conflict experienced by Ben, ultimately justifying unsustainable transport practices.

A notion of deservingness also connects us with Cohen's typology again, in that implicatory denial can productively be understood, in the context of our data, as distributed 
across a much broader terrain of activity than empirical work to date suggests. It involves the emplotment of behaviour in a narrative identity that involves ongoing 'calculations' of ethical balance (Wilk, 2010). Therefore, the complex discourses surrounding 'deservingness', the holiday as a treat, and strategies of 'displaced commitment' all function to legitimise air transport for tourism in Ben's account.

It is a form of implicatory denial because the implications of climate change are filtered through a lens of individualised accountability, but that responsibilisation can then be managed - (de)prioritised, hierarchised, mitigated - just as many other individual responsibilities are, through narratives of deservingness, sacrifices, treats and so on. Such processes might be thought of as psychological or internal, but here they are constructed interpersonally in dialogue and discourse. Furthermore, it is established cultural narratives of individualisation and consumerism that make such discourse meaningful and valid - an extension of the 'stocks of knowledge' Norgaard describes in her ethnographic work (Norgaard, 2006; 2011).

Indeed, in an interview with Anna, a similar discursive defence of her air transport practices was offered when she explicitly states she is aware of the issues of air transport but through her tendency to "walk a lot and use public transport" whilst away, she is able to negotiate such conflict through the ethical decisions she made in other transport decisions. In another interview, Darren comments on how he is keen to avoid flying but "I might fly like every third or fourth year". In a similar light, Julie diffused the challenge to her tourism transport behaviours through her account in which she stated "it's not like we are popping across for a week... I don't fly very much and I don't do lots of short haul flights I feel quite strongly that that is wrong..." Hannah's response is analogous:

I didn't because we haven't flown, I mean the last time we flew anywhere was when we went to Sardinia umm, three nearly four years ago umm so that was the last time we flew anywhere and before that probably about three or four years before that so it's not something we make a habit of and, I think my view is that if you only do it occasionally it is acceptable

All participants justify air travel by 'balancing' it against a strong commitment to the environmental cause, made evident through reference to self-regulation of air transport as a norm, generating a sense of deservingness, via moral accounting, and holding onto a positive self-image. Thus, the interplay between anxiety and self-representation maintain and rely upon complex discursive barriers to individual engagement with sustainable transport futures.

\section{Pockets of resistance and the potential to overcome tourism barriers}

Whilst the previous sections of the analysis have shown the ways in which dominant discourses function to legitimise forms of social denial and facilitate the continuation of air 
transport practices, we also identified alternative narratives in our data from some of the participants. For example, in relation to her overland trip to India, Gemma highlights how her social identity facilitates a different understanding of travel and transport to that of many of her peers. As she comments:

I have been surrounded by a lot of people who are interested in ethical issues for a long time and one of the main things that gets talked about is flying so it feels like it would be ridiculous if you spent 18 years of your life learning about how you shouldn't fly and then as soon as you get the chance just jet off round the world like so many do, yeah, I just didn't want to fly so had to try to find a different way to get there...I quite like flying (h) it's not because I don't...

Throughout Gemma's account she draws strongly on her social ethical identity through reference to her life being 'surrounded' by individuals "who are interested in ethical issues" and "learning about how you shouldn't fly". Such constructions of her identity reflect a very different set of resources from which she is able to understand and rationalise her air transport decisions. Here then, Gemma is not simply constructing an account in which she develops her identity through affiliation to a group which is deemed to be 'better' than another (Tajfel \& Turner, 1979). Rather, this affiliation, and active involvement in the movement, is motivated by the "...responsibility of maintaining or reviving" (Foucault, 1992, p. 27) a particular tradition of which one is heir to. Therefore, for Gemma we can see that the 'sustainable' traditions of family members and friends have "surrounded her" and enabled her to establish a relationship to herself and the broader environment. Thus, she recognises herself in relation to the morality of her social group and experiences an obligation to put this to practice, in conjunction with a relationship with her own 'feelings' (e.g. her wants and desires). In this sense, whilst we have seen more prominent discourses creating barriers towards sustainable practices, here we also see how very similar discourses surrounding social identities might enable sustainable practices.

Another example of an alternative discourse surrounding decisions to/not to fly can be seen in the understanding of transport as a means to an end for many tourists and how such a notion can indeed be resisted. As Katy, a 22-year-old female whom did an overland trip to Syria, comments when reflecting on her experience:

so, you see the like with trains you see the landscape change and you see the people change and you know you actually have a feeling that you have gone a really long way whereas when you get on a plane you know you get on it and 5 hours later you get off it and it's just a bit easy and yeah you don't get that feeling of distance

In this quote Katy actively resists the contemporary notion that the holiday is an event at a location and the mode of transport is often simply understood as one hurdle standing in 
the way of the experience (Jensen, Scarles, \& Cohen, 2015). Rather, Katy draws her proximal relationship to the changing landscape and people throughout her overland travels as something which she actively embraces, an understanding central to the contemporary concept of 'slow travel' (J. Dickinson \& Lumsdon, 2010). Here the experience of "feeling that you have gone a really long way" is presented as something central to her overall tourist satisfaction. The disconnect from physical space through air transport on the other hand is presented as something which Katy dislikes and thus such a way of talking about modes of transport in the tourist process appear to actively facilitate more sustainable practices.

In the extract below Francesca, an individual who embarked on a coast-to-coast walking holiday in the UK, was asked if she had any further comments to add at the end of the interview and responded with the following:

(F) you know all this cutting back is a waste of time and we are just making our lives more difficult and in a way, it's like you know what I haven't even got kids and like maybe I should, maybe I should just say bugger it and just go and buy whatever I want, and fly wherever I want and stop worrying about and stop it having impact on my life because it's not going to save anything anyway you know

(I) yeah

(F) so, I can see how other people and me as well you know the attraction to giving it all up really when you go on holiday is quite seductive

Here Francesca negotiates the 'sustainable tourist' identity by an extreme case formulation of that identity ("all this cutting back"; "giving it all up") and its binary opposite ("buy whatever I want and fly wherever I want"); followed by an assertion of her own powerlessness ("a waste of time"; "it's not going to save anything anyway"); which is effectively a way of diminishing one's (or anyone's) sense of responsibility - all identified as 'types of denial' in previous research (Stoll-Kleemann et al., 2001). Minimised responsibility is amplified by what is pejoratively categorised as 'self-righteous comparisons' (Norgaard, 2006b, 2011; Opotow \& Weiss, 2000) - "I haven’t even got kids" (i.e. those who have children are more responsible) - which counters the assertion of powerlessness, but makes some more responsible than others. Again, the implications of one act (flying) are minimised by being located in a constellation of acts, which in this case takes in the imagined actions of countless others (having kids). As seen previously, the rhetorical question "you know" is repeatedly deployed, creating the sense that such ways of talking, and ultimately acting, are common sense and common knowledge (Kurz et al., 2005).

However, in her closing sentence Francesca draws on these discourses not to legitimise her identity as 'inactive', but rather the opposite. She draws on an empathetic account of her understanding as to how many individuals are seduced by such ways of thinking, particularly in relation to the holiday space as a pursuit of hedonistic pleasure and relaxation. This empathy enables Francesca to position herself as someone that understands the ways in which 
environmental action and inaction are constructed, and ultimately the barriers individuals face when making sustainable transport decisions.

Finally, through an engagement with the notion of the 'staycation' (e.g. Wixon, 2009) Amanda talks of her previous flying practices resulting in extreme guilt and "various apocalyptic thoughts", she then goes on to utilise a more positive understanding that "actually not flying is really kind of it opens your eyes to the what's on your door step". In addition, reflecting on her previous long-haul lifestyle flying to countries such as India and China, Christina talks of how she not only gave up flying but also "ditched" her car which made her "realise that I wanted to sort of, explore locally a bit more". Whilst the 'staycation' discourse appears marginalised throughout our data it does however highlight another possible narrative and a positive discursive facilitator to potentially help overcome the discursive barriers exposed earlier in this analysis.

\section{Discussion}

As is highlighted in this special issue and elsewhere (e.g. Metz et al., 2016; Poullikkas, 2015), in contemporary tourism transport, there is technology to offer new sustainable transport futures which may help to mitigate some of the negative environmental impacts more commonly associated with tourism transport (e.g. air transport) (Hall et al., 2013). However, as we also noted at the start of this paper, there is existing evidence of an attitude-behaviour gap which often results in available 'sustainable behaviour' options not being taken up. In addition, the introduction to this paper highlighted how tourism research has shown there is a general misunderstanding of tourism transport impacts amongst tourists (Becken, 2007), alongside what has been understood as cognitive dissonance in relation to tourist behaviours and attitudes (Miller et al., 2010), and distinct issues with the tourism context for sustainable touristic and transport behaviours (Barr et al., 2010; Hares et al., 2010; Randles \& Mander, 2009). On this basis, we suggested that (social) psychoanalytic understandings of self-representation and denial might usefully enrich this debate to explore the ways in which discursive barriers exist in relation to tourism transport practices.

Throughout the analysis it was demonstrated that contemporary discourses circulating in relation to tourism transport and the notion of the 'holiday' do indeed function to legitimise and maintain socially organised forms of denial in relation to flying behaviours, even with a sample of individuals whom explicitly identified as 'sustainable'. Whilst tensions were present for the individuals in relation to their transport practices having negative impacts on the environment, ultimately such practices are still adopted.

In fact, adopting Cohen's typology of denial provides us with a framework, admittedly speculative at this stage, for understanding how those tensions are negotiated for those who self-identity as 'green', environmentally-minded etc. It may well be that literal and interpretive denial are effectively 'blocked-off' as discursive strategies for the liberal and progressively-minded individuals explicitly seeking out sustainable tourism - as identified in Figure 1. Perhaps assertions that climate change is happening, that it is caused by humans, 
and that it effects and implications are significant are unlikely to be denied, or at least denied outright in polite conversation. Whilst the retention of ambiguity and uncertainty should not be underestimated in contributing to interpretive denial, the remaining form of denial denying the implications of climate change becomes fruitful territory here. This is especially so for defending against the dissonance arising from awareness of the (un)sustainability of one's own practices. In fact, it is possible that implicatory denial strategies may actually be heightened (e.g. projection and splitting) in this context. Thus, if we are to attempt to engage with the challenge of developing more desirable transport futures, attention needs to not only focus on the types of transport available, but also the discursive, socially organized barriers that might hinder the uptake of such desirable transport futures.

Future research would benefit from taking on board the ways in which socially organized denial locks individuals into particular practices despite their potential desire to change. Such an understanding could be explored in relation to a range of tourism related transport systems to isolate how each specific practice is constructed through a specific set of discourses and resulting practices. Moreover, as we show in our final section of the analysis, there exist 'pockets of resistance'. Here the ways in which individuals draw on alternative narratives to present the practice of flying as an undesirable element to the tourist experience through either a strong identification with a social and ethical identity, a desire to experience travel through space/place, a rejection that we are powerless, or through an understanding of the types of tourist experiences 'on your door-step'.

By exposing dominant discursive barriers, but also highlighting moments of 'resistance', we suggest that there lies the potential for challenging the more prominent socially organized forms of denial. Here we are warned against an over-deterministic reading of the processes involved in the social organization of denial, and reminded that it does not exclude the possibility of alternative expressions, discourses and narrative frames emerging. The emphasis here is on ways of constructing sustainable and unsustainable practices that routinely deny their implications in various ways; but they must not be thought of as exhaustive. For example, in the promotion of tourism perhaps more emphasis is needed in positioning the mode of transport as a central element to the tourist experience as opposed to a hurdle to their experience. It would also be beneficial for those leading the tourism transport industry to attempt to address the issues and move away from the types of discourses highlighted by Gössling and Peeters (2007) as these inevitably circulate through to the potential tourist. In addition, by turning to comprehensive theories attempting to understand the 'psychosocial' self, we can further enrich our understanding of why tourists engage in particular tourism related travel practices.

Finally, considering the diverse utilization of the concept of sustainability, it appears there is still value in adhering to the social constructionist tenet that defining it is a contingent, ongoing process that can serve many purposes. It is therefore necessary to 'examine the ways in which particular parties may employ the concept differently in order to achieve certain political ends' (Kurz et al., 2005, p. 604); and, we would add, interrelated social and personal ends. Understanding "the shared contemporary socio-discursive meanings that construct outcomes of a practice as desirable or required" is still, we feel, a neglected 
area, and one that has not to date been adequately addressed (Kurz, Gardner, Verplanken, \& Abraham, 2015, p. 115).

\section{References}

Adams, M. (2014). Approaching Nature,'Sustainability'and Ecological Crises from a Critical Social Psychological Perspective. Social and Personality Psychology Compass, 8(6), 251-262.

Adams, M. (2016). Ecological crisis, sustainability \& the psychosocial subject. Basingstoke: Palgrave.

Adams, M., \& Raisborough, J. (2008). What can sociology say about FairTrade? Situating reflexivity in ethical consumption. Sociology., 42(6), 1165-1182.

Bagnoli, A. (2004). Researching Identities with Multi-method Autobiographies Sociological Research Online, 9(2). $<$ http://www.socresonline.org.uk/9/2/bagnoli.html $>$

Barber, N. A. (2014). Profiling the Potential "Green" Hotel Guest: Who Are They and What Do They Want? Journal of Hospitality and Tourism Research, 38(3), 361-387.

Barr, S., Shaw, G., Coles, T., \& Prillwitz, J. (2010). 'A holiday is a holiday': practicing sustainability, home and away. Journal of Transport Geography, 18(3), 474-481.

Becken, S. (2004). How Tourists and Tourism Experts Perceive Climate Change and Carbonoffsetting Schemes. Journal of Sustainable Tourism, 12, 332-345.

Becken, S. (2007). Tourists' perception of international air travel's impact on the global climate and potential climate change policies. Journal of Sustainable Tourism, 15(4), 351-368.

Bedford, T., Burningham, K., Cooper, G., Green, N., \& Jackson, T. (2011). Sustainable Leisure: Escalations, Constraints and Implications. RESOLVE Working Paper Series: University of Surrey.

Blackman, J. S. (2004). 101 defenses: How the mind shields itself. Hove: Psychology Press.

Bowers, J. (2016). Developing sustainable tourism through ecomuseology: a case study in the Rupununi region of Guyana. Journal of Sustainable Tourism, 24(5), 758-782.

Butler, R. (1998). Sustainable tourism - looking backwards in order to progress? In M. Hall \& A. Lew (Eds.), Sustainable Tourism: A Geographical Perspective. Harlow: Pearson Education Limited.

Caruana, R., Crane, A., \& Fitchett, J. (2008). Paradoxes of consumer independence: a critical discourse analysis of the independent traveller. Marketing Theory, 8, 253.

Chan, W. W., \& Lam, J. C. (2003). Energy-saving supporting tourism sustainability: A case study of hotel swimming pool heat pump. Journal of Sustainable Tourism, 11(1), 74-83.

Cohen, S. (2012). Discussion: Climate change in a perverse culture. In S. Weintrobe (Ed.), Engaging with Climate Change: Psychoanalytic and Interdisciplinary Perspectives (Vol. 72-79).

London: Routledge.

Cohen, S. (2013 [2001]). States of denial: Knowing about atrocities and suffering. Cambridge: Polity Press.

Cohen, S. (1996). Government responses to human rights reports: Claims, denials, and counterclaims. Human Rights Quarterly, 18(3), 517-543.

Cooper, G., Green, N., Burningham, K., Evans, K., \& Jackson, T. (2012). Unravelling the Threads: Discourses of Sustainability and Consumption in an Online Forum. Environmental Communication, 6(1), 101-118.

Croall, J. (1995). Preserve or Destroy: Tourism and the Environment. London: Calouste Gulbenkian Foundation. 
Darnton, A., Verplanken, B., White, P., \& Whitmarsh, L. (2011). Habits, Routines and Sustainable Lifestyles: A summary report to the Department for Environment, Food and Rural Affairs. London: AD Research and Analysis for DEFRA.

Davison, L. (2012, 29-30th August 2012). 'Staycations': What are the drivers to holidaying at home? Paper presented at the ITRN, Ulster.

Deakin, H., \& Wakefield, K. (2013). SKYPE interviewing: reflections of two PhD researchers. Qualitative Research, Online, 1-14.

Dickinson, J., \& Lumsdon, L. (2010). Slow travel and tourism. London: Earthscan.

Dickinson, J. L. (2009). The people paradox: Self-esteem striving, immortality ideologies, and human response to climate change. Ecology and Society, 14(1), 34.

Dillard, J. E., \& Bates, D. L. (2011). Leisure motivation revisited: why people recreate. Managing Lesiure, 16(4), 253-268.

Dolnicar, S. (2004). Beyond “commonsense segmentation": A systematics of segmentation approaches in tourism. Journal of Travel Research, 42(3), 244-250.

Dolnicar, S. (2010). Identifying tourists with smaller environmental footprints. Journal of Sustainable Tourism, 18, 717-734.

Dolnicar, S., Crouch, G., \& Long, P. (2008). Environment-friendly Tourists: What Do We Really Know About Them? Journal of Sustainable Tourism, 16, 197-210.

Dolnicar, S., \& Leisch, F. (2008). An Investigation of Tourists' Patterns of Obligation to Protect the Environment. Journal of Travel Research, 46, 381-391.

Dunlap, R. E., \& Jacques, P. J. (2013). Climate change denial books and conservative think tanks: exploring the connection. American Behavioral Scientist, 57(6), 699-731.

Edwards, D. (2000). Extreme case formulations: Softeners, investment, and doing nonliteral. Research on language and social interaction, 33(4), 347-373.

Evans, D., \& Jackson, T. (2007). Towards a Sociology of Sustainable Lifestyles. RESOLVE Working Paper Series 03-07: University of Surrey.

Festinger, L., \& Carlsmith, J. M. (1959). Cognitive consequences of forced compliance. The Journal of Abnormal and Social Psychology, 58(2), 203-210.

Fielding, K. S., Terry, D. J., Masser, B. M., \& Hogg, M. A. (2008). Integrating social identity theory and the theory of planned behaviour to explain decisions to engage in sustainable agricultural practices. British Journal of Social Psychology, 47(1), 23-48.

Foucault, M. (1992). The Use of Pleasure: The History of Sexuality, Volume 2. (R. Hurley, Trans). London: Penguin.

France, L. A. (1997). The Earthscan reader in sustainable tourism. London: Earthscan.

Freud, A. (1992). The ego and the mechanisms of defence (Vol. Revised). London: Karnac Books.

Freud, S. (1894). The defense neuro-psychoses. Collected papers, 1, 59.

Freudenburg, W. R., \& Muselli, V. (2013). Reexamining Climate Change Debates: Scientific Disagreement or Scientific Certainty Argumentation Methods (SCAMs)? American Behavioral Scientist, 57, 777-795.

Gergen, K., \& Gergen, M. (1986). Narrative form and the construction of psychological science. In T. R. Sarbin (Ed.), Narrative psychology: The stories nature of human conduct. New York: Praeger.

Gifford, R. (2011). The dragons of inaction: Psychological barriers that limit climate change mitigation and adaptation. American Psychologist, 66(4), 290.

Gifford, R., \& Nilsson, A. (2014). Personal and social factors that influence pro-environmental concern and behaviour: A review. International Journal of Psychology, 49(3), 141-157. 
Gössling, S., Broderick, J., Upham, P., Ceron, J.-P., Dubois, G., Peeters, P., \& Strasdas, W. (2007). Voluntary Carbon Offsetting Schemes for Aviation: Efficiency, Credibility and Sustainable Tourism. Journal of Sustainable Tourism, 15, 223-248.

Gössling, S., \& Peeters, P. (2007). 'It does not harm the environment!'An analysis of industry discourses on tourism, air travel and the environment. Journal of Sustainable Tourism, 15(4), 402-417.

Gronau, W. (2016). Encouraging behavioural change towards sustainable tourism: a German approach to free public transport for tourists. Journal of Sustainable Tourism, 1-11.

Hall, C. M., Scott, D., \& Gössling, S. (2013). The primacy of climate change for sustainable international tourism. Sustainable Development, 21(2), 112-121.

Hamilton, C. (2013). What history can teach us about climate change denial. In S. Weintrobe (Ed.), Engaging with climate change: Psychoanalytic \& interdisciplinary prespectives (pp. 16-32). London: Routledge.

Hanna, P. (2012). Using internet technologies (such as Skype) as a research medium: a research note. Qualitative Research, 12(2), 239-242.

Hanna, P., Scarles, C., Cohen, S., \& Adams, M. (2016). Everyday climate discourses and sustainable tourism. Journal of Sustainable Tourism, Online First. doi: 10.1080/09669582.2015.1136636

Hares, A., Dickinson, J., \& Wilkes, K. (2010). Climate change and the air travel decisions of UK tourists. Journal of Transport Geography, 18(3), 466-473.

Hartmann, D., Tank, A., \& Rusticucci, M. (2013). IPCC fifth assessment report, climate change 2013: The physical science basis. IPCC AR5, 31-39.

Higgins-Desbiolles, F. (2008). Justice Tourism and Alternative Globalisation. Journal of Sustainable Tourism, 16, 345-364.

Hollander, N. C. (2009). When not knowing allies with destructiveness: global warning and psychoanalytic ethical non-neutrality. International Journal of Applied Psychoanalytic Studies, 6(1), 1-11.

Holt, A. (2010). Using telephones for narrative interviewing: A Research Note. Qualitative Research, 10, 113-121.

Hugh-Jones, S., \& Madill, A. (2009). The air's got to be far cleaner here: A discursive analysis of place-identity threat. British Journal of Social Psychology, 48(4), 601-624.

Hunter, C. (2002a). Aspects of the Sustainable Tourism Debate from a Natural Resource Perspective. In R. Harris, T. Griffin \& P. Williams (Eds.), Sustainable Tourism: A Global Perspective. Oxford: Butterworth-Heinemann.

Hunter, C. (2002b). Sustainable tourism and the touristic ecological footprint. Environment, Development and Sustainability, 4, 7-20.

Imran, M., \& Pearce, J. (2015). Discursive barriers to sustainable transport in New Zealand cities. Urban Policy and Research, 33(4), 392-415.

Jacques, P. J., Dunlap, R. E., \& Freeman, M. (2008). The organisation of denial: Conservative think tanks and environmental scepticism. Environmental politics, 17(3), 349-385.

Jensen, M. T., Scarles, C., \& Cohen, S. A. (2015). A multisensory phenomenology of interrail mobilities. Annals of Tourism Research, 53, 61-76.

Johnston, P., Everard, M., Santillo, D., \& Robèrt, K.-H. (2007). Reclaiming the definition of sustainability. Environmental science and pollution research international, 14(1), 60-66.

Juvan, E., \& Dolnicar, S. (2014). The attitude-behaviour gap in sustainable tourism. Annals of Tourism Research, 48, 76-95.

Klein, N. (2015) This changes everything: Capitalism vs. the climate. Harmondsworth: Penguin 
Kollmuss, A., \& Agyeman, J. (2002). Mind the gap: why do people act environmentally and what are the barriers to pro-environmental behavior? Environmental Education Research, 8(3), 239260.

Koteyko, N., Jaspal, R., \& Nerlich, B. (2013). Climate change and 'climategate' in online reader comments: a mixed methods study. The Geographical Journal, 179(1), 74-86.

Kramer, U. (2010). Coping and defence mechanisms: What's the difference?-Second act. Psychology and Psychotherapy: Theory, Research and Practice, 83(2), 207-221.

Kurz, T., Donaghue, N., Rapley, M., \& Walker, I. (2005). The ways that people talk about natural resources: Discursive strategies as barriers to environmentally sustainable practices. British Journal of Social Psychology, 44(4), 603-620.

Kurz, T., Gardner, B., Verplanken, B., \& Abraham, C. (2015). Habitual behaviors or patterns of practice? Explaining and changing repetitive climate-relevant actions. Wiley Interdisciplinary Reviews: Climate Change, 6(1), 113-128.

Lakoff, G. (2010). Why it matters how we frame the environment. Environmental Communication, $4(1), 70-81$.

Larson, L. R., \& Poudyal, N. C. (2012). Developing sustainable tourism through adaptive resource management: A case study of Machu Picchu, Peru. Journal of Sustainable Tourism, 20(7), 917-938.

Lawler, S. (2008). Identity: Sociological Perspectives. Cambridge: Polity Press.

Leggett, W. (2014). The politics of behaviour change: Nudge, neoliberalism and the state. Policy \& Politics, 41(1), 3-19.

Lertzman, R. (2010). Psychoanalysis, culture, society and our biotic relations: Introducing an ongoing theme on environment and sustainability. Psychoanalysis, Culture \& Society, 15(2), 113-116.

Lorenzoni, I., Nicholson-Cole, S., \& Whitmarsh, L. (2007). Barriers perceived to engaging with climate change among the UK public and their policy implications. Global Environmental Change, 17(3), 445-459.

Luzar, E. J., Diagne, A., Ecgan, C., \& Henning, B. (1998). Profiling the Nature-Based Tourist: A Multinominal Logit Approach. Journal of Travel Research, 37, 48-55.

Magnini, V. P., Crotts, J. C., \& Zehrer, A. (2011). Understanding customer delight an application of travel blog analysis. Journal of Travel Research, 50(5), 535-545.

McGehee, N. G., \& Meares, A. C. (1998). A case study of three tourism-related craft marketing cooperatives in Appalachia: Contributions to community. Journal of Sustainable Tourism, 6(1), 4-25.

Merritt, A. C., Effron, D. A., \& Monin, B. (2010). Moral self-licensing: When being good frees us to be bad. Social and Personality Psychology Compass, 4(5), 344-357.

Metz, S., Sohr, A., Bei, X., Wölki, M., \& Behrisch, M. (2016). Sustainable transport development in mega cities by transferring new mobility concepts to developing countries. Transportation Research Procedia.

Micheletti, M. (2003). Political Virtue and Shopping: Individuals, Consumerism and Collective Action. Basingstoke: Palgrave.

Miller, G., Rathouse, K., Scarles, C., Holmes, K., \& Tribe, J. (2010). Public understanding of sustainable tourism. Annals of Tourism Research, 37(3), 627-645.

Mowforth, M., \& Munt, I. (2003). Tourism and Sustainability: Development and new tourism in the third world. (2nd ed.). London: Routledge.

Norgaard, K. (2006a). "People Want to Protect Themselves a Little Bit": Emotions, Denial, and Social Movement Nonparticipation*. Sociological inquiry, 76(3), 372-396. 
Norgaard, K. (2006b). "We Don't Really Want to Know" Environmental Justice and Socially Organized Denial of Global Warming in Norway. Organization \& Environment, 19(3), 347370.

Norgaard, K. (2011). Living in denial: Climate change, emotions, and everyday life: MIT Press. Ochs, E., \& Capps, L. (1996). Narrating the Self. Annual Review of Anthropology, 25, 19-43.

Opdenakker, R. (2006). Advantages and disadvantages of four interview techniques in qualitative research. Paper presented at the Forum Qualitative Sozialforschung/Forum: Qualitative Social Research.

Opotow, S., \& Weiss, L. (2000). New ways of thinking about environmentalism: Denial and the process of moral exclusion in environmental conflict. Journal of Social Issues, 56(3), 475490.

Potter, J., \& Wetherell, M. (1987). Discourse and Social Psychology: Beyond attitudes and behaviour. London: Sage.

Poullikkas, A. (2015). Sustainable options for electric vehicle technologies. Renewable and Sustainable Energy Reviews, 41, 1277-1287.

Rabinovich, A., Morton, T. A., Postmes, T., \& Verplanken, B. (2012). Collective self and individual choice: The effects of inter-group comparative context on environmental values and behaviour. British Journal of Social Psychology, 51(4), 551-569.

Randall, R. (2009). Loss and climate change: The cost of parallel narratives. Ecopsychology, 1(3), 118-129.

Randles, S., \& Mander, S. (2009). Aviation, consumption and the climate change debate: 'Are you going to tell me off for flying?'. Technology analysis \& strategic management, 21(1), 93-113.

Rappaport, J., \& Stewart, E. (1997). A critical look at critical psychology: elaborating the questions. In D. Fox \& I. Prilleltensky (Eds.), Critical Psychology: An introduction. London: Sage.

Rustin, M. (2010). Looking for the unexpected: Psychoanalytic understanding and politics. British Journal of Psychotherapy, 26(4), 472-479.

Sayer, A. (2012). Power, Sustainability and Well Being: An Outsider's View. In E. A. Shove \& N. Spurling (Eds.), Sustainable Practices: Social Theory and Climate Change (pp. 167-181). London: Routledge.

Scarles, C. (2012). The Photographed Other: interplays of agency in tourist photography in Cusco, Peru. Annals of Tourism Research, 39(2), 928-950.

Shove, E. A. (2010). Beyond the ABC: Climate Change Policy and Theories of Social Change. Environment and Planning A, 42(6), 1273-1285.

Simon, L., Greenberg, J., \& Brehm, J. (1995). Trivialization: the forgotten mode of dissonance reduction. Journal of personality and social psychology, 68(2), 247.

Soron, D. (2010). Sustainability, self-identity and the sociology of consumption. Sustainable Development, 18(3), 172-181.

Speer, S. A., \& Potter, J. (2000). The management of heterosexist talk: Conversational resources and prejudiced claims. Discourse \& Society, 11(4), 543-572.

Sperling, S. J. (1958). On denial and the essential nature of defence. The International journal of psycho-analysis, 39, 25.

Spurling, N., McMeekin, A., Shove, E., Southerton, D., \& Welch, D. (2013). Interventions in practice: Re-framing policy approaches to consumer behaviour: Sustainable Practices Research Group Report.

Stoll-Kleemann, S., O'Riordan, T., \& Jaeger, C. C. (2001). The psychology of denial concerning climate mitigation measures: evidence from Swiss focus groups. Global Environmental Change, 11(2), 107-117. 
Tajfel, H., \& Turner, J. C. (1979). An Intergrative Theory of Social Contact'. In W. Austin, Worchel, S. (Ed.), The Social Psychology of Intergroup Relations. Monterey: Brooks/Cole.

UNEP. (2014). Environmental Impacts of Tourism - Global Level. Retrieved 15/08/2014, from http://www.unep.org/resourceefficiency/Business/SectoralActivities/Tourism/TheTourismand EnvironmentProgramme/FactsandFiguresaboutTourism/ImpactsofTourism/EnvironmentalIm pacts/EnvironmentalImpactsofTourism-GlobalLevel/tabid/78777/Default.aspx

Uzzell, D., \& Räthzel, N. (2009). Transforming environmental psychology. Journal of Environmental Psychology, 29(3), 340-350.

Van Liere, K. D., \& Dunlap, R. E. (1980). The Social Basis of Environmental Concern: A Review of Hypotheses: Explanation and Emperical Evidence. Public opinion quarterly, 44, 181-199.

Warde, A. (2005). Consumption and Theories of Practice. Journal of Consumer Culture, 5(2), 131153.

Warde, A. (2013). Sustainable Consumption and Behaviour Change. Discover Society, 1, 1-5.

Weaver, D. (2006). Sustainable Tourism: Theory and Practice. Elsevier Butterworth-Heinemann: Oxford.

Weintrobe, S. (2010). Engaging with climate change means engaging with our human nature. Ecopsychology, 2(2), 119-120.

White, R., \& Stirling, A. (2013). Sustaining trajectories towards Sustainability: Dynamics and diversity in UK communal growing activities. Global Environmental Change, 23(5), 838-846.

Wilk, R. (2010). Consumption embedded in culture and language: implications for finding sustainability. Sustainability: Science, Practice, \& Policy, 6(2), 38-48.

Willig, C. (2008). Discourse Analysis. In J. Smith (Ed.), Qualitative Psychology: A practicle guide to research methods (2nd ed.). London: Sage.

Wixon, M. (2009). The great American staycation: How to make a vacation at home fun for the whole family (and your wallet!). Avon, MA: Adams Media.

Yeoman, I., Brass, D., \& McMahon-Beattie, U. (2007). Current issue in tourism: The authentic tourist. Tourism Management, 28, 1128-1138. 
Table 1. Participants and types of denial

\begin{tabular}{|l|l|l|l|}
\hline Amanda & 28 & $\begin{array}{l}\text { 'WWOOFING' (Willing Workers On } \\
\text { Organic Farms) in France }\end{array}$ & Resistance \\
\hline Anna & 59 & Volunteering in Quito & $\begin{array}{l}\text { Literal, interpretative \& } \\
\text { implicatory denial }\end{array}$ \\
\hline Ben & 52 & $\begin{array}{l}\text { Holiday to Greece through } \\
\text { responsibletravel.com }\end{array}$ & Implicatory denial \\
\hline Carly & 26 & $\begin{array}{l}\text { Long distance walking and camping in UK } \\
\text { \& holiday in India }\end{array}$ & Implicatory denial \\
\hline Celia & 23 & Eco-friendly yoga retreat in France & Resistance \\
\hline Christina & 37 & Camping at Unicorn camps in the UK & Resistance \\
\hline Darren & 29 & Inter-rail to Budapest visiting 2 communes & Implicatory denial \\
\hline Denise & 60 & Intrepid package to China & Implicatory denial \\
\hline Francesca & 41 & Coast to coast walking holiday in the UK & Resistance \\
\hline Gemma & 20 & $\begin{array}{l}\text { Overland tour and WWOOFING in Europe, } \\
\text { Russia, China, Mongolia and India }\end{array}$ & Resistance \\
\hline Gillian & 25 & Eco-resort on Andros Islands & literal and interpretive denial \\
\hline Hannah & 57 & Intrepid package to India & Implicatory denial \\
\hline James & 37 & Green holiday in eco-caravan in UK & Resistance \\
\hline Jayne & 48 & Eco-holiday to Sri Lanka & Implicatory denial \\
\hline Julie & 27 & Conservation project in Madagascar & Implicatory denial \\
\hline Katy & 22 & $\begin{array}{l}\text { Overland travel to Syria using only local } \\
\text { shops, hotels etc. }\end{array}$ & Resistance \\
\hline
\end{tabular}


Figure 1. Types of denial, discursive strategies \& socially organized denial

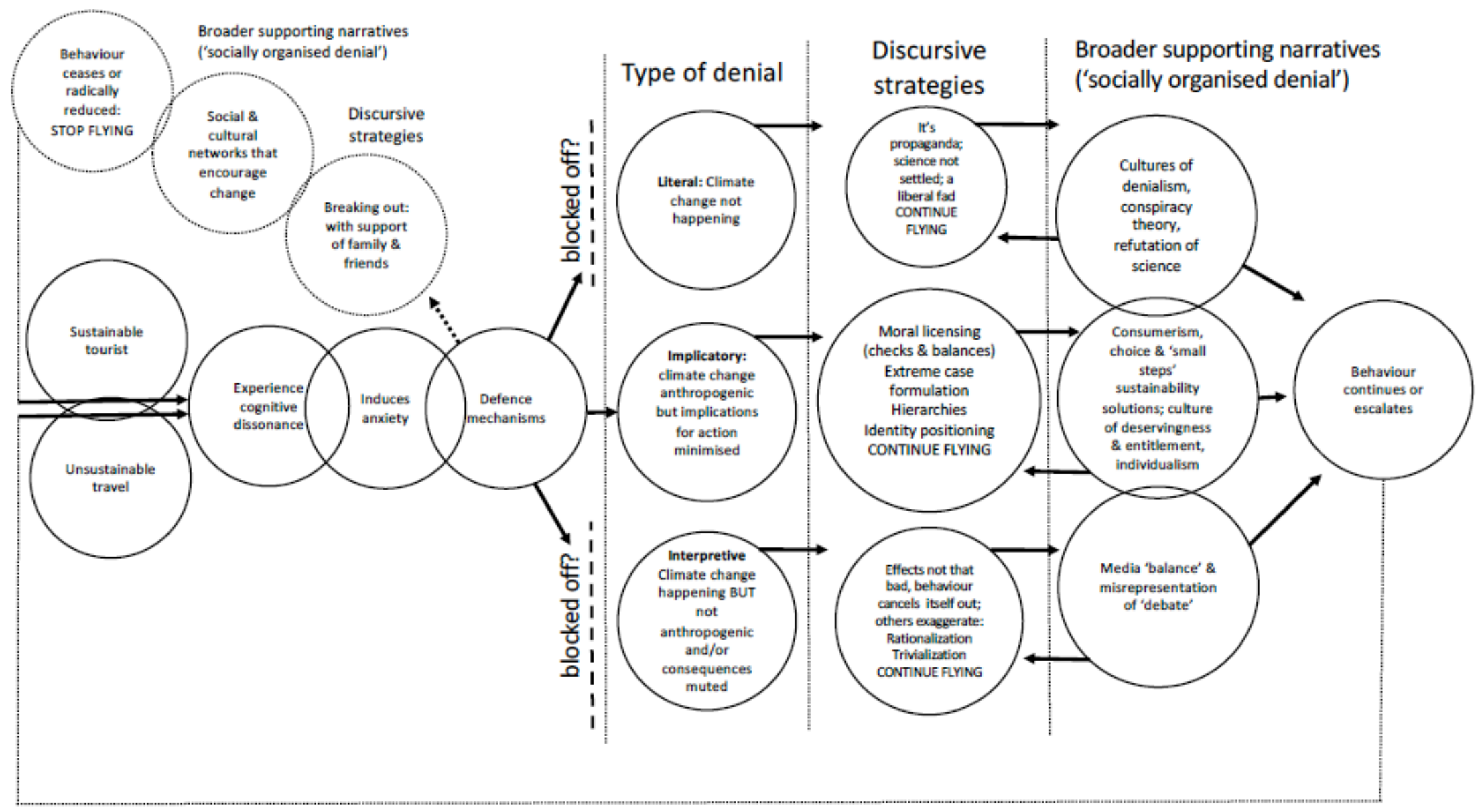


Author pre-proof version 